\title{
The effect of reduced vowel working space on speech intelligibility in Mandarin-speaking young adults with cerebral palsy
}

\author{
Huei-Mei Liu ${ }^{\text {a) }}$ \\ Department of Special Education, National Taiwan Normal University, Taiwan 98195 \\ Feng-Ming Tsao \\ Department of Psychology, National Taiwan University, Taiwan \\ Patricia K. Kuhl \\ The Institute for Learning and Brain Sciences, University of Washington, Seattle, Washington
}

(Received 24 April 2004; revised 7 March 2005; accepted 8 March 2005)

\begin{abstract}
The purpose of this study was to examine the effect of reduced vowel working space on dysarthric talkers' speech intelligibility using both acoustic and perceptual approaches. In experiment 1 , the acoustic-perceptual relationship between vowel working space area and speech intelligibility was examined in Mandarin-speaking young adults with cerebral palsy. Subjects read aloud 18 bisyllabic words containing the vowels $/ \mathrm{i} / \mathrm{h} / \mathrm{a} /$, and /u/ using their normal speaking rate. Each talker's words were identified by three normal listeners. The percentage of correct vowel and word identification were calculated as vowel intelligibility and word intelligibility, respectively. Results revealed that talkers with cerebral palsy exhibited smaller vowel working space areas compared to ten age-matched controls. The vowel working space area was significantly correlated with vowel intelligibility $(r=0.632, p<0.005)$ and with word intelligibility $(r=0.684, p<0.005)$. Experiment 2 examined whether tokens of expanded vowel working spaces were perceived as better vowel exemplars and represented with greater perceptual spaces than tokens of reduced vowel working spaces. The results of the perceptual experiment support this prediction. The distorted vowels of talkers with cerebral palsy compose a smaller acoustic space that results in shrunken intervowel perceptual distances for listeners. (C) 2005 Acoustical Society of America.
\end{abstract}

[DOI: 10.1121/1.1898623]

PACS numbers: 43.70.Dn, 43.70. $-\mathrm{h}$, 43.71.Gv [RLD] Pages: 3879-3889

\section{INTRODUCTION}

A combination of both perceptual and acoustic analyses has revealed that using phonetic contrasts to explore dysarthric speech is a valid, sensitive, and reliable method to identify the critical acoustic-phonetic distortions that contribute to speech intelligibility deficits (Kent et al., 1989; Kent et al., 1997; Weismer and Martin, 1992; Yorkston, Dowden, and Beukelman, 1992). This acoustic-perceptual approach not only assesses overall communicative efficiency but also analyzes the characteristics of dysarthric speech to point out underlying speech-motor movement restrictions that are not easily identified from perceptual judgments. This study aimed to analyze the effect of restricted vowel acoustic space on speech intelligibility.

Cerebral palsy, a nonprogressive neuromuscular disorder, is usually associated with a variety of motor speech problems classified in a generic category, dysarthria (Hardy, 1983; McDonald, 1987). Approximately 30\%-90\% of talkers with cerebral palsy have some dysarthric speech and reduced speech intelligibility (Yorkston, Beukelman, and Bell, 1988). Disturbances in articulatory coordination of the lips, tongue, mandible, and velum in talkers with cerebral palsy have been reported (Kent, Netsell, and Abbs, 1978). These

${ }^{a)}$ Electronic mail: liumei@cc.ntnu.edu.tw distorted physiologic mechanisms of speech appear to adversely affect intelligibility.

Perceptual studies using minimal phonetic contrasts to assess the relative contributions of individual phonetic cues to overall speech intelligibility have shown that vowel clarity can be a very potent predictor of speech intelligibility for dysarthric speech (e.g., Kent et al., 1989; Weismer and Martin, 1992). For example, the clarity of high-low, front-back, and long-short vowel contrasts are highly correlated with word intelligibility (Ansel and Kent, 1992; Liu, Tseng, and Tsao, 2000; Whitehill and Ciocca, 2000). Though vowel errors can decrease speech intelligibility, they seem less severe when compared to more problematic consonant contrasts (Platt, Andrews, and Howie, 1980; Platt et al., 1980).

Furthermore, the important acoustic cues for distinguishing minimal contrasts among vowels, such as duration, first formant $(F 1)$, second formant $(F 2)$, and $F 2-F 1$ differences, were also shown to account for much of the variance in word intelligibility (Bunton and Weismer, 2001; Turner, Tjaden, and Weismer, 1995; Weismer et al., 2001). This suggested that distorted acoustic features for vowels, such as extremely long duration, distorted formant location, and atypical formant slope, were highly associated with the speech intelligibility deficits in speakers with dysarthria.

Other studies analyzing dysarthric speech have also found that distorted vowels adversely affect intelligibility 
(Ansel and Kent, 1992; Liu et al., 2000; Whitehill and Ciocca, 2000). Ansel and Kent (1992) investigated the speech intelligibility of 16 male adults diagnosed with mixed-type cerebral palsy, showing that the acoustic correlates of all vowel contrasts tested (i.e., high-low, front-back, and laxtense) significantly contributed to overall speech intelligibility. Liu and colleagues (2000) assessed the weightings of six minimal phonetic contrasts on speech intelligibility of Mandarin-speaking young adults with cerebral palsy. They found that the segmental intelligibility of a front-back vowel contrast and its acoustic correlate (i.e., the formant frequency difference between $F 1$ and $F 2$ ) contributed greatly to overall speech intelligibility. In addition, Whitehill and Ciocca (2000) used principal component analysis and found that vowel contrasts were combined as an important component accounting for the total variance of intelligibility. These acoustic and perceptual findings on speech intelligibility of talkers with cerebral palsy have consistently demonstrated that imprecise vowel articulation greatly reduced intelligibility.

\section{A. Vowel working space and vowel intelligibility}

Vowels are quasiperiodic sounds, and the formant pattern of a given vowel determines its phonetic quality and reflects the articulatory configuration that produced it (Stevens, 1998). Generally, $F 1$ varies mostly with tongue height such that the higher the tongue position, the lower the $F 1$ frequency, while $F 2$ varies mostly with tongue advancement; the more anterior the tongue position, the higher the $F 2$ and larger $F 2$ to $F 1$ difference (Kent, Dembowski, and Lass, 1995; Stevens, 1998).

Vowel working space area can be seen as an index of the accuracy of vowel articulation, which signifies gross motor control ability of the tongue and jaw coordination. To examine the vowel working spaces of individual talkers, the "corner" vowels, such as $/ \mathrm{i} /, / \mathrm{a} /$, and $/ \mathrm{u} /$, are frequently selected because these vowels are the most common in human languages (Ladefoged and Maddieson, 1996). In addition, these vowels are perceptually and acoustically exceptional because they represent the extreme positions in a talker's articulatory vowel working space, and hence extreme formant frequency values in acoustic space (Lindblom, 1990).

Restricted size of the vowel working space enclosed by the first two formants of three or four corner vowels has been shown in dysarthric speech for talkers with amyotrophic lateral sclerosis (ALS) (Weismer et al., 1992; 2001), traumatic brain injury (Ziegler and von Cramon, 1983, 1986), and even for children with dysarthria (Hodge, 1999; Higgins and Hodge, 2001). Moreover, studies have reported a positive relationship between speech intelligibility and the area of vowel working space formed by the corner vowels /i/, /æ/, $/ \mathrm{a} /$, and $/ \mathrm{u} /$ on the $F 1 / F 2$ coordinates for English-speaking adults with dysarthric speech (Turner et al., 1995; Weismer et al., 2000).

In addition to atypical talkers, normal American talkers who produced larger vowel working spaces were generally judged to be more intelligible than talkers with smaller spaces (Bradlow, Torretta, and Pisoni, 1996). Relatively expanded vowel working space was observed for clear speech compared to conservational speech, while speaking rate remained similar (Krause and Braida, 2004). Moreover, recent acoustic-phonetic work on assessing vowel exaggeration in caregivers' speech directed to infants demonstrated that the vowel working space was significantly larger in infantdirected speech than in adult-directed speech (Kuhl et al., 1997; Burnham, Kitamura, and Vollmer-Conna, 2002; Liu, Kuhl, and Tsao, 2003). Thus, the area of vowel working space may affect perceived speech intelligibility and could serve as a measure of talker variability. In other words, vowel working space area may indicate speech intelligibility and the overall severity of speech impairment for talkers with dysarthria.

Although many studies have assessed vowel working space area for American English-speaking adults with dysarthria, there is a paucity of literature on Mandarin talkers with dysarthria. Mandarin Chinese is a tonal language in which every syllable must carry a lexical tone, a suprasegmental element that serves to signify meaning. The primary acoustic correlate of tones is fundamental frequency $(F 0)$. Compared to 14 vowels of American English, there are 8 different vowels of Mandarin Chinese. Although the numbers of vowels vary between languages, the vowel system of Mandarin Chinese, similar to most of the vowel systems in the world, includes high and low, front and back, and rounded and unrounded contrasts (Howie, 1976; Tseng, 1990). To test the universality of restricted vowel working space on speech intelligibility, the systematic investigation of acousticperceptual association in dysarthric speech must be extended to more languages. The target language of this study, Mandarin Chinese, is currently spoken by more than one billion people. Despite the widespread use of Mandarin Chinese, there has been a very limited amount of work of segmental acoustics in adults with cerebral palsy in this language (Liu et al., 2000).

The first experiment of this study examined the relationship between vowel working space area and overall speech intelligibility in Mandarin talkers with cerebral palsy, to examine how well the data from English talkers with dysarthria generalize to another language population.

\section{B. Vowel working space, perceptual organization, and speech intelligibility}

The acoustic-perceptual analysis of the relationship between vowel working space area and speech intelligibility sheds light on how an individual talker's reduced vowel working space can affect listeners' identification of speech sounds. However, correlational analyses may not be able to fully determine the effect of reduced vowel working space on speech intelligibility. Additional speech features, such as breathy voice, inconsistent vocal intensity, and unstable speaking rate of vowels (e.g., Kent et al., 1978) common in dysarthric speech can combine with restricted vowel working space to reduce speech intelligibility. Besides, the perceptual organization of listeners perceiving distorted acoustic signals with reduced vowel working space is unclear. The perceptual organization of speech sounds is an essential element of phonetic representation and crucial to the processing of acoustic input (Eimas and Miller, 1992; Remez, 2001). Studies have 
shown that the perception of phonetic category goodness affects internal phonetic organization when listeners were engaged in speech judgments. For example, perceptual distance shrinks around good exemplars but expands around poor exemplars when physical distances are kept constant among tokens (Iverson and Kuhl, 1996; Iverson et al., 2003). It is reasonable to hypothesize that the distorted vowels in dysarthric speech may occupy less dispersed perceptual space than typical vowels. In other words, speech sounds from talkers with reduced vowel working space may be associated with a smaller perceptual space, resulting in a negative impact on the judgment of speech intelligibility.

Few acoustic-phonetic studies on dysarthric speech have attempted to assess the effect of reduced vowel working space on listeners' perceptual organization of speech sounds. Determining the specific features that contribute to decreased speech intelligibility has not only theoretical value for the field of speech perception, but also has clinical implications. The combination of both acoustic and perceptual analysis should provide a better understanding of the causes of reduced speech intelligibility and could facilitate clinical interventions to improve intelligibility in this population. To further evaluate the role of vowel working space area on speech intelligibility, this study also systematically manipulated the vowel working space area to assess its effect on the perceptual organization of speech sounds.

The goal of the present study was to examine the effect of reduced vowel working space on dysarthric talkers' speech intelligibility using both acoustic-phonetic and perceptual approaches. Two related experiments were conducted. In experiment 1, the relationship between the area of vowel acoustic space and speech intelligibility was examined in 20 Mandarin-speaking young adults with cerebral palsy. A positive relationship between the enclosed area of corner vowels in the $F 1 / F 2$ space and speech intelligibility should support a generalization of the findings of previous studies on English-speaking talkers with dysarthria to other languages. In experiment 2, vowel working space area was systematically manipulated to further examine the impact of reduced vowel working space area on overall speech intelligibility. To support the hypothesis that reduced vowel working space negatively affects the speech intelligibility, poor vowel exemplars (i.e., tokens of a relatively reduced vowel working space) are expected to be represented with smaller perceptual spaces than those of good exemplars (i.e., tokens of a relatively larger vowel working space).

\section{EXPERIMENT 1: THE RELATIONSHIP BETWEEN VOWEL WORKING SPACE AND SPEECH INTELLIGIBILITY}

\section{A. Methods}

\section{Participants}

The talkers were 20 male young adults referred by school speech-language pathologists and diagnosed with cerebral palsy and various degrees of speech deficits. Their ages ranged from 17 years to 22 years old ( $M$ $=18.5$ years). Each talker was judged as having adequate intelligence and hearing ability to perform the speech record- ing task based on health records and experimenter's observation. In addition, data were collected from ten agematched neurologically intact controls who participated in the same speech recording task.

\section{Speech materials}

A total of 18 ( 3 vowels $\times 6$ words) high-frequency bisyllabic words was chosen from a Chinese word database (Wu and Liu, 1987) for speech recording and acoustic analysis. The frequencies of these Mandarin Chinese bisyllabic words were controlled. They contained the target vowels, /i/, /a/, and $/ \mathrm{u} /$, in the first syllable. The bisyllabic target words were constructed as $\mathbf{C V C V}(\mathrm{V})$, in which the syllable-final vowel could be a monophthong or a diphthong and the tone numeral was attached to the end of each syllable, such as [tí4tau4] vs. [ta 4 tau4]. These 18 target words can be grouped into to three minimal-phonemic word pairs for each vowel contrast, /i/-/a/, /u/-/a/, and /i/-/u/, to better control for neighboring phonemic environment. The point vowel, /i/, $/ \mathrm{a} /$, or $/ \mathrm{u} /$, in the first syllable of each word was the target vowel for acoustic analysis. These 18 vowel-contrast words were taken from a Mandarin word intelligibility test used in a previous study (Liu et al., 2000).

\section{Recording procedures}

During the recording, talkers were seated in a quiet recording room. Each of the 18 words was printed individually on a card. Before the recording, subjects were instructed to go through the 18 words to make sure that they knew the words. The presentation sequences of words were block randomized across talkers to decrease the talker's awareness of phonemic contrasts during speech recording. Talkers were asked to read each word aloud using a normal speaking rate in a comfortable situation. To control the speaking rate of individual talkers, an experimenter turned over each printed card for the talker, inducing an interword interval of about 3 s. Speech samples were tape recorded on a cassette recorder (Nakamichi 550). These speech samples were used as stimuli for both intelligibility judgments and acoustic analysis.

\section{Speech intelligibility measures}

An item identification task was employed for measuring speech intelligibility. Sixty listeners used Chinese characters to orthographically transcribe speech samples produced by 20 talkers with cerebral palsy. To control for the influence of familiarity with dysarthric speech on intelligibility judgments, none of the listeners was familiar with dysarthric speech. Three listeners simultaneously transcribed speech samples of one talker and none of these listeners heard more than one talker. In total, $60(3 \times 20)$ undergraduate students with normal hearing served as judges for the subjects with cerebral palsy. For the ten normal speakers, $30(3 \times 10)$ undergraduate students with normal hearing served as judges.

Two intelligibility scores were calculated based on the correct identification of the phonemes within 18 bisyllabic words for individual talkers. The percentage of correct vowel identifications was used as a measure of vowel intelligibility. 
Likewise, the percent correct of the word identifications, i.e., correct identification of all phonemes of the bisyllabic word, was calculated as word intelligibility. The intelligibility scores, including the vowel intelligibility and word intelligibility, for each talker were averaged from the scores of the three judges. Given that two intelligibility scores were collected, the word intelligibility score was used to represent individual talkers' speech intelligibility in this study.

In addition to identifying the percentage of correct phonemes for one individual talker, all 60 listeners also transcribed a subset of the same three words randomly selected from one talker with cerebral palsy whose word intelligibility was about $50 \%$. This was done to assess interjudge reliability, which was relatively high, Cronbach $\alpha=0.95$. The same interjudge reliability procedure was utilized to assess the reliability for normal speakers. The reliability was also relatively high, Cronbach $\alpha=0.997$.

\section{Acoustic analysis procedures}

The first and second formant frequencies ( $F 1$ and $F 2$ ) of corner vowels $(/ \mathrm{i} /, / \mathrm{a} /$, and $/ \mathrm{u} /)$ contained in 18 target words produced by talkers with cerebral-palsy and normal talkers were measured. All formant measurements were conducted using a 486 DX2-66 PC with a speech analyzer, the Kay Elemetrics' Computerized Speech Laboratory (CSL) Software CSL-4300B. The target words were low-pass filtered at $8 \mathrm{kHz}$ and sampled at a rate of $20 \mathrm{kHz}$. Both the linear prediction coding (LPC) spectra and wideband spectrograms were used to determine the locations of first two formants. The onset of each vowel segment was marked when both $F 1$ and $F 2$ became visible on the spectrogram. Vowel offset was marked at a point where $F 2$ and/or $F 1$ were no longer visible. A third marker was placed at the durational center of each vowel segment. Vowel formant frequencies were measured at the cursor that marked the central position of a vowel segment. If the LPC method did not clearly locate the vowel formants (because of vocal irregularities), the fast Fourier transform (FFT) spectra were derived as a supplementary analysis of vowel spectra.

After obtaining the formant frequencies of the three corner vowels $/ \mathrm{i} /, / \mathrm{a} /$, and $/ \mathrm{u} /$, average $F 1$ and $F 2$ values for each vowel were plotted on an $F 1 / F 2$ plane to provide quantitative indices of "acoustic vowel working space area" of individual talkers. The $F 1$ and $F 2$ pairs of each vowel were viewed as coordinates in the $x-y$ plane and the area was calculated using the following equation:

$$
\begin{aligned}
\text { Vowel triangle area }= & \operatorname{ABS}\left\{\left[F 1 \mathrm{i}^{*}(F 2 \mathrm{a}-F 2 \mathrm{u})\right.\right. \\
& +F 1 \mathrm{a}^{*}(F 2 \mathrm{u}-F 2 \mathrm{i})+F 1 \mathrm{u}^{*}(F 2 \mathrm{i} \\
& -F 2 \mathrm{a})] / 2\},
\end{aligned}
$$

where "ABS" is absolute value, " $F 1 \mathrm{i}$ " symbolizes the $F 1$ value of vowel $/ \mathrm{i} /$, " $F 2 \mathrm{a}$ " symbolizes the $F 2$ value of vowel $/ \mathrm{a} /, \ldots$, and so on.

Interjudge reliability of acoustic analysis was controlled in two ways. First, before analyzing the dysarthric speech samples, reliability between the experimenter and another person who was proficient in acoustic analysis was calculated on $10 \%$ of a normal talker's vowel samples. The inter- judge reliability of this acoustic analysis procedure was 0.94 . The average differences between judges were $25 \mathrm{~Hz}(4.6 \%)$ and $84 \mathrm{~Hz}(4.1 \%)$ for $F 1$ and $F 2$, respectively. Second, $10 \%$ of the measurements of the dysarthric vowel samples were used to calculate the interjudge reliability. The interjudge reliability of this acoustic analysis procedure was 0.91 . The average differences between judges were $41 \mathrm{~Hz}(5.9 \%)$ and $103 \mathrm{~Hz}(5.1 \%)$ for $F 1$ and $F 2$, respectively.

\section{B. Results and discussions}

\section{Speech intelligibility scores}

Intelligibility scores of talkers with cerebral palsy are reported in Table I. The intelligibility scores of 20 talkers with cerebral palsy obtained from the item-identification task varied greatly across individuals (for word intelligibility, ranged from $24 \%$ to $88 \%, M=56 \%, \mathrm{SD}=20.75$; for vowel intelligibility, ranged from $35 \%$ to $100 \%, M=78 \%$, SD $=17.87$ ). This result indicates that talkers in this study represent a wide-range severity of speech impairment. Compared to the great variation among individuals with cerebral palsy, normal speakers' intelligibility scores were in a narrower range (for word intelligibility, $M=96.6 \%, \mathrm{SD}=2.02$, range $=92.2 \%-99.3 \% ;$ for vowel intelligibility, $M$ $=99.8 \%, \mathrm{SD}=0.59$, range $=98.1 \%-100 \%)$. In addition, across all 20 talkers with cerebral palsy, the vowel intelligibility scores were highly correlated with word intelligibility $(r=0.86, p<0.0001)$.

\section{Vowel working space characteristics}

Results of the vowel working space area encompassing $/ \mathrm{i} /, / \mathrm{a} /$, and $/ \mathrm{u} /$ of individual talkers show that 20 talkers with cerebral palsy exhibited significantly smaller vowel working space areas when compared to ten age-matched controls, $F(1,28)=13.025, p<0.001$, Hedges's $g=1.36$. Figure 1 displays more centralized vowel dispersions for talkers with cerebral palsy compared to those in the normal control group. The reduced vowel working space area represents a restriction of tongue elevation and front-back movement for talkers with cerebral palsy. Statistical analyses on vowel formants provide further support.

For the talkers with cerebral palsy, the low vowel /a/ exhibited significantly lower $F 1$ frequency ( $M$ $=729 \mathrm{~Hz}, \mathrm{SD}=109 \mathrm{~Hz}$ ) than was found for normal talkers $[M=803 \mathrm{~Hz}, \mathrm{SD}=55 \mathrm{~Hz} F(1,28)=3.98, p<0.01$, Hedges's $g=0.75]$. Conversely, the average $F 1$ value of the high vowel /i/ in talkers with cerebral palsy $(M=313 \mathrm{H}, \mathrm{SD}$ $=31 \mathrm{~Hz}$ ) was significantly higher than that of normal talkers $[M=277 \mathrm{~Hz}, \mathrm{SD}=24 \mathrm{~Hz} F(1,28)=8.85, p<0.01$, Hedges's $g=1.12]$. $F 1$ variation is primarily associated with tongue height during vowel production (Peterson and Barney, 1952; Hillenbrand et al., 1995). The narrower range of $F 1$ values for the high-low vowel contrast $(/ \mathrm{i} /-/ \mathrm{a} /), F(1,28)=8.11, p$ $<0.01$, Hedges's $g=1.07$, implies that talkers with cerebral palsy have more limited jaw/tongue vertical movement compared to normal talkers.

In vowels from talkers with cerebral palsy, the $F 2-F 1$ difference was $1844 \mathrm{~Hz}(\mathrm{SD}=190)$ for the high-front vowel /i/ and it was $569 \mathrm{~Hz}(\mathrm{SD}=93)$ for the high-back vowel /u/. 
TABLE I. Descriptive data for 20 male cerebral-palsied subjects.

\begin{tabular}{|c|c|c|c|c|c|c|}
\hline Subject & Age & Classification & $\begin{array}{l}\text { Severity of } \\
\text { impairment }\end{array}$ & $\begin{array}{c}\text { Word } \\
\text { intelligibility } \\
(\%)\end{array}$ & $\begin{array}{c}\text { Vowel } \\
\text { intelligibility } \\
(\%)\end{array}$ & $\begin{array}{c}\text { Vowel } \\
\text { space area } \\
\left(\mathrm{Hz}^{2}\right)\end{array}$ \\
\hline $\mathrm{CP} 1$ & 19 & Athetoid & Moderate & 59 & 69 & 205539 \\
\hline $\mathrm{CP} 2$ & 19 & Spastic & Moderate & 24 & 35 & 164606 \\
\hline CP3 & 19 & Spastic & Moderate & 36 & 57 & 238559 \\
\hline $\mathrm{CP} 4$ & 17 & Ataxic & Moderate & 74 & 85 & 348575 \\
\hline CP5 & 18 & Tremor & Moderate & 32 & 76 & 291836 \\
\hline CP6 & 19 & Mixed & Moderate & 26 & 54 & 115005 \\
\hline CP7 & 22 & Mixed & Severe & 35 & 63 & 111157 \\
\hline CP 8 & 18 & Spastic & Moderate & 83 & 93 & 376995 \\
\hline CP 9 & 20 & Spastic & Moderate & 84 & 98 & 353263 \\
\hline CP 10 & 18 & Spastic & Mild & 55 & 81 & 125456 \\
\hline CP 11 & 17 & Spastic & Mild & 88 & 100 & 296440 \\
\hline CP 12 & 18 & Athetoid & Moderate & 53 & 91 & 269073 \\
\hline CP 13 & 18 & Athetoid & Mild & 50 & 83 & 129092 \\
\hline CP 14 & 19 & Athetoid & Moderate & 56 & 65 & 193306 \\
\hline CP 15 & 18 & Spastic & Moderate & 44 & 78 & 280635 \\
\hline CP 16 & 20 & Spastic & Severe & 74 & 96 & 362846 \\
\hline CP 17 & 18 & Athetoid & Severe & 44 & 67 & 145937 \\
\hline CP 18 & 18 & Tremor & Moderate & 84 & 96 & 396053 \\
\hline CP 19 & 18 & Athetoid & Severe & 45 & 69 & 287416 \\
\hline CP 20 & 17 & Spastic & Moderate & 75 & 100 & 228411 \\
\hline
\end{tabular}

When compared to normal talkers (/i/, $\mathrm{M}=2075 \mathrm{~Hz}, \mathrm{SD}$ $=132$; and $/ \mathrm{u} /, \mathrm{M}=478 \mathrm{~Hz}, \mathrm{SD}=39$ ), talkers with cerebral palsy demonstrated a significantly narrower range of $F 2-F 1$ values for the front-back vowel contrast $(/ \mathrm{i} /-/ \mathrm{u} /), F(1,28)$ $=15.18, p<0.001$, Hedges's $g=1.47$. Given that $F 2$ or $F 2-F 1$ difference varies mostly with tongue advancement, the more anterior the tongue position, the higher the $F 2$ and larger $F 2-F 1$ difference; the reduced range of $F 2-F 1$ indicates more restricted front-back tongue movement (Kent,

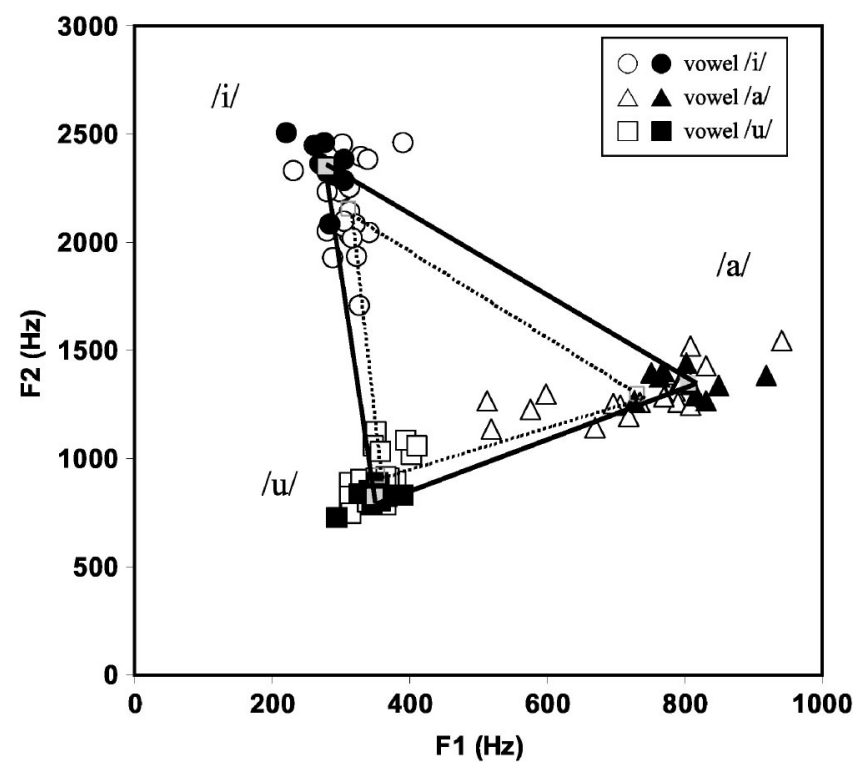

FIG. 1. Vowel working spaces of Mandarin talkers with normal speech and cerebral palsy. Vowel working spaces formed by the average of the $F 1$ and $F 2$ values for the vowels /i/, /a/, and /u/. Data points represent the mean coordinate of the first two formant frequencies of the vowels /i/, /a/, and /u/ produced by normal talkers (closed) versus talkers with cerebral palsy (open). Each data point represents the average of one talker's vowel productions. A decrease of the vowel working space is observed in talkers with cerebral palsy (dashed line).
Dembowski, and Lass, 1995; Stevens, 1998). Taken together, the smaller vowel working space and more centralized articulation reflect more restricted vertical and horizontal tongue movements in talkers with cerebral palsy compared to normal talkers during vowel production.

\section{The relationship between vowel working space area and speech intelligibility}

To generalize the previous findings on the relationship between articulation space and speech intelligibility, the correlational analysis for Mandarin talkers with cerebral palsy was expected to demonstrate positive correlations between vowel working space area and speech intelligibility. The results of the analysis support this prediction. Vowel working space area was significantly correlated with the vowel intelligibility $(r=0.632, p<0.005)$ and with word intelligibility $(r=0.684, p<0.005)$.

In experiment 1 , talkers with relatively larger vowel working spaces were judged to be more intelligible than talkers with reduced vowel working spaces. Therefore, vowel working space area could be a general indicator of speech intelligibility. Larger vowel working spaces have been shown to correlate with better speech intelligibility in typical talkers (Bradlow et al., 1996). Also, smaller vowel working space area is commonly found in English speakers with dysarthria, secondary to disorders such as amyotrophic lateral sclerosis (ALS) (Turner et al., 1995; Weismer et al., 2001) and traumatic brain injury (Ziegler and von Cramon, 1983, 1986). These results of acoustic analysis on Mandarin talkers with cerebral palsy suggest that vowel working space area is important in the prediction of intelligibility in talkers with dysarthria of this type. 


\section{EXPERIMENT 2: EFFECTS OF REDUCED VOWEL WORKING SPACE ON LISTENERS' PERCEPTUAL ORGANIZATION}

Speech intelligibility is a global measure, reflecting the cumulative effects of various acoustic-phonetic features on listeners' perceptual judgments. In experiment 1 , results of the acoustic analysis showed that vowel working space area is strongly associated with speech intelligibility for talkers with cerebral palsy. Experiment 2 was designed to examine the effects of reduced acoustic vowel working space on normal listeners' perceptual organization through the manipulation of vowel working space area, while controlling for other speech characteristics across vowel tokens.

The stimulus set for this experiment consisted of synthesized /i/, /a/, and /u/ vowels varying in $F 1$ and $F 2$ frequencies. Six vowel triangles were generated with similar shape but different areas. The largest of these variants created vowel working spaces that corresponded to actual vowel working spaces of the most intelligible dysarthric speech in experiment 1 . The smallest vowel working space was even smaller than that of the least intelligible talker in the previous experiment. During the experimental session, participants identified each token as $/ \mathrm{i} /, / \mathrm{a} /$, or $/ \mathrm{u} /$, and rated the category goodness of each token on a 7-point scale. Subjects then completed an AX discrimination task in which they judged whether the tokens in each pair were the same or different.

Reaction times in the discrimination task were analyzed by multidimensional scaling (MDS) to map the perceptual organization underlying these stimuli and illustrate the correspondence between discrimination and goodness with finer detail. MDS is repeatedly shown to be effective at modeling perceptual similarity of vowels (Singh and Woods, 1971; Shepard, 1972; Fox, 1983; Kewley-Port and Atal, 1989). Various measures can be utilized to estimate raw similarity, including similarity judgments of sound pairs on a numerical scale, identification-confusion percentage (more frequent confusions for similar vowels), and reaction time measures (longer reaction times for more similar sounds). MDS assigns stimuli to a geometric space where distances in the Euclidean configuration correspond to perceived similarity (Borg and Groenen, 1997). In the MDS configuration, stimuli are constructed along major axes (dimensions) that are perpendicular to each other. Stimuli perceived as similar are close to each other in MDS space and stimuli perceived as dissimilar are further apart. Modeling similarity using MDS analysis uncovers relationships among stimuli that are difficult to observe solely from raw similarity ratings.

To support the prediction that restricted vowel working space area would affect speech intelligibility, the vowels of the largest vowel triangle were expected to be judged as more intelligible and rated as having higher "goodness" than those of the smallest vowel triangle. Moreover, the MDS was expected to show that perceptual distances between vowels of smaller triangles would be smaller than those of larger vowel triangles in the perceptual organization of normal listeners.

\section{A. Methods}

\section{Participants}

Twenty-two undergraduates (ten women) at universities in Taiwan were recruited from a solicitation posted on the Internet. A language background questionnaire was administrated before the experiment to ensure that Mandarin Chinese was the native or the dominant language for all participants. Participants reported no history of communication disorders and received $\$ 15$ for their participation in this 1-h experiment.

\section{Stimuli}

The stimuli were 18 vowel tokens (three corner vowels /i/, /a/, and $/ \mathrm{u} / \times$ six variants) created using HLSYN speech synthesizer 2.2 (1996) and sampled at $11025 \mathrm{~Hz}$. Vowel variants were synthesized by manipulating the values of the first and second formants; the third, fourth, and fifth formants remained constant for the same phonetic category. Figure 2 shows the spatial relationship of point vowel variants on $F 1 / F 2$ space. The psychoacoustic distances between neighboring tokens were equalized at 30 mels in $F 1 / F 2$ vowel working space. The mel scale is essentially linear at low frequencies and logarithmic at high frequencies, and corresponds well to excitation patterns of the ear's basilar membrane. Fant (1973) argued that the mel scale was appropriate for vowels because the minimum perceptible differences were similar for the first three formants when measured in mels. Thus, vowel variants among neighboring tokens were scaled in this common metric.

The $F 1$ and $F 2$ values of the most intelligible talker with cerebral palsy (subject: CP11, vowel intelligibility $=100 \%$, word intelligibility $=88 \%$ ) in experiment 1 were utilized as the starting point to generate vowel variants in 30 -mel steps. Then, the $F 1$ and $F 2$ values were gradually adjusted to reduce the vowel working space areas. The smallest vowel triangle of the synthesized vowel $\left(85190 \mathrm{~Hz}^{2}\right)$ was smaller than the smallest vowel triangle of a talker with the cerebral palsy in experiment 1 (subject: CP7, area $=111157 \mathrm{~Hz}^{2}$ ). The spatial relationship on the $F 1 / F 2$ plane of these synthesized vowel triangles was similar to that of the vowel triangles of normal talkers and talkers with cerebral palsy shown in Fig. 1 of experiment 1 .

Table II lists the $F 1$ and $F 2$ values of vowel variants in mels. For /i/, $F 1$ values increased from 298 to $367 \mathrm{~Hz}$ and $F 2$ values decreased from 2232 to $1954 \mathrm{~Hz}$; for /a/, F1 decreased from 794 to $623 \mathrm{~Hz}$ and $F 2$ decreased from 1355 to $1292 \mathrm{~Hz}$; for /u/, F1 increased from 370 to $443 \mathrm{~Hz}$ and $F 2$ increased from 910 to $1090 \mathrm{~Hz}$. The $F 3$ and $F 4$ values were 3186 and $3755 \mathrm{~Hz}$ for the /i/ variants, respectively; 2633 and $3648 \mathrm{~Hz}$ for the /a/ variants; and 2449 and $3518 \mathrm{~Hz}$ for the /u/ variants. The $F 0$ of all tokens was $120 \mathrm{~Hz}$ and each vowel was $450 \mathrm{~ms}$ long. Mandarin Chinese is a tonal language, meaning that changes of pitch contours sign different lexical meanings for syllables. The $F 0$ of vowel tokens did not change over time, so that the lexical tone pattern was similar to the high-level tone in Mandarin Chinese. The stimuli were equalized in rms power and played to subjects at a comfortable level of approximately $70 \mathrm{~dB}$ SPL. 
TABLE II. $F 1$ and $F 2$ values (in mels) of synthetic vowel variants in experiment 2 . The psychoacoustic distances between tokens were equalized at 30 mels in $F 1 / F 2$ vowel working space. $F 1$ and $F 2$ values of the most intelligible vowels in experiment 1 were utilized as the starting point to generate vowel variants.

\begin{tabular}{|c|c|c|c|c|c|c|}
\hline \multirow{2}{*}{$\begin{array}{l}\text { Psychoacoustic distances (in } \\
\text { mels) from the clearest vowel }\end{array}$} & \multicolumn{2}{|c|}{ /i/ } & \multicolumn{2}{|c|}{ /a/ } & \multicolumn{2}{|c|}{$/ \mathrm{u} /$} \\
\hline & $F 1$ & $F 2$ & $F 1$ & $F 2$ & $F 1$ & $F 2$ \\
\hline 0 & 376 & 1692 & 843 & 1236 & 454 & 934 \\
\hline 30 & 391 & 1666 & 814 & 1228 & 469 & 960 \\
\hline 60 & 406 & 1640 & 785 & 1220 & 484 & 985 \\
\hline 90 & 421 & 1614 & 756 & 1212 & 499 & 1011 \\
\hline 120 & 436 & 1588 & 727 & 1205 & 514 & 1037 \\
\hline 150 & 451 & 1563 & 698 & 1197 & 529 & 1063 \\
\hline
\end{tabular}

\section{Apparatus}

The stimuli were presented and controlled by an Intel Pentium III laptop computer (Dell Inspiron 4100). The vowels were played bilaterally to subjects using noise-reduction headphones (Bose QuietComfort Acoustic Noise Canceling headset) while subjects were sitting in a sound-treated room. Subjects' responses were entered and recorded using the computer that controlled the presentation of stimuli.

\section{Procedure}

a. Phonetic identification and goodness ratings. Twenty participants were asked to identify each token as /i/, /a/, or /u/. After identification, they were asked to rate each token on a scale from 1 (poor) to 7 (good) regarding its goodness as a member of that phonetic category. At the start of the experiment, participants completed a practice session of 18 trials with each of the tokens presented once in a random order. After the practice, participants completed an experimental session of 36 trials ( 2 blocks of 18 tokens) with the order of trials randomized within each block.

b. Phonetic similarity judgment. Participants heard all possible pairs of the 18 tokens in an AX discrimination task. On each trial, the participant heard two tokens separated by $550 \mathrm{~ms}$ and were asked to decide whether the vowels in each pair of stimuli were the same or different. Their response for each trial (same or different) and reaction time (RT) were recorded. RTs on different trials were utilized as similarity scores and submitted to the multidimensional scaling (MDS) solution to create a perceptual map where the distance between any two tokens corresponded to perceived similarity.

Prior to the test, participants completed a short practice session. There were 12 "same" trials and 24 "different" trials chosen randomly from the trials used in the experimental session. The practice trials were the same as in the experimental session except that participants received feedback on their responses. During the test stage, 378 test pairs $(=306$ different trials and 72 same trials) were presented with no feedback. The same trials consisted of four trials of each of the 18 tokens. The 306 different trials consisted of each possible pair of the 18 tokens and the probability of presentation order, i.e., $\mathrm{A}-\mathrm{B}$ and $\mathrm{B}-\mathrm{A}$, was equal. Participants were allowed to take a short break after every 40 trials; the entire session took 30 to $40 \mathrm{~min}$ to complete.

\section{B. Results and discussion}

\section{Phonetic identification and goodness ratings}

Figure 2 displays the results of phonetic identification and goodness ratings. There is high intersubject agreement on goodness rating (Cronbach $\alpha=0.95$ ) and phonetic identification for each vowel token (average identification percentage $=96.3 \%$ ). Tokens with formant frequencies similar to the most intelligible vowels in experiment 1 were rated as better exemplars of vowel categories. Moreover, goodness judgments varied with vowel area in the $F 1 / F 2$ space. As shown in Fig. 2, tokens composing larger vowel working spaces were generally judged as the better vowel exemplars. The tokens comprising the largest vowel triangle were judged to be the best exemplars for /i/ and /a/, and second best for $/ \mathrm{u} /$. In contrast, tokens composing the smallest vowel triangle were judged to be the poorest exemplars for each vowel category. Goodness ratings varied significantly within each vowel at the significance level of 0.001 in one-way repeated measure analyses of variance (ANOVAs), /i/, $F(5,95)=39.22 ; / \mathrm{a} /, F(5,95)=22.97 ; / \mathrm{u} /, F(5,95)=13.47$. Although there are equal psychophysical differences between neighboring tokens, tokens close to typical vowels in the $F 1 / F 2$ space receive similar goodness ratings. A posthoc LSD analysis at $p=0.05$ demonstrates that the goodness ratings of better exemplars did not differ significantly for the three best (of six) /i/ tokens, the four best (of six) /a/ tokens, and the two best (of six) $/ \mathrm{u} /$ tokens. The finding that vowels

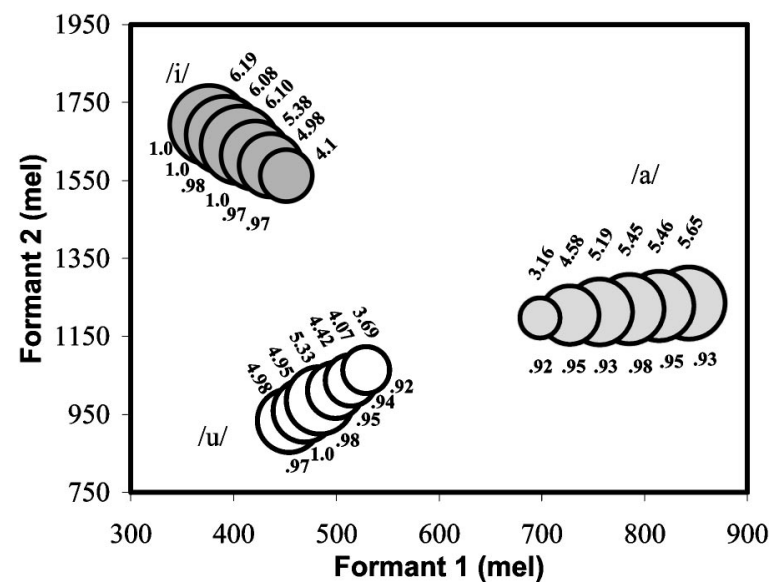

FIG. 2. Identification and goodness ratings for Mandarin vowels. For each token, the upper number lists goodness rating and the bottom number displays percent-correct identification. Circle size corresponds to perceived goodness. 
composing larger acoustic space were judged to be better exemplars than vowels of smaller vowel triangles provides support for the prediction that vowel working space area greatly affects vowel intelligibility and goodness ratings.

Token goodness varies with acoustic vowel area. However, the shrunken acoustic space of synthesized tokens does not greatly affect the percentage of vowel identification (Fig. 2 ). The relatively stable identification percentages across tokens could reveal the categorical aspect of phonetic identification (e.g., Liberman et al., 1961). However, the high identification percentage $(>90 \%)$ of tokens of the smallest vowel triangle could also be a result of the forced-choice identification task. The identification for tokens in the most restricted vowel space might be less consistent if participants were allowed to free-identify tokens as any one of the Mandarin vowels because their formant patterns were located at the adjacent area of different vowels on the $F 1 / F 2$ space, e.g., the $/ \mathrm{i} /$ and $/ \mathrm{y} /$.

\section{Similarity judgments and perceptual organization}

Each subject's responses were put into the form of a lower triangular matrix composed of the log RT for each pair of tokens averaged across the presentation order. Responses to "same" trials were not considered in the analyses. Overall subject accuracy was $85.01 \%$. Subjects correctly detected the stimulus pairs that were different on $87.2 \%$ of the trials and had false alarms on $17.2 \%$ of the trials of same sound pairs. Intersubject reliability was done to assess the consistency of RTs across all pairs of tokens. There was high agreement for response latencies on judging differences across all pairs (Cronbach $\alpha=0.98$ ).

The lower triangular matrix of log RTs was submitted to the ALSCAL (Takane, Young, and de Leeuw, 1977) MDS algorithm implemented by SPSS 10.0 (statistical software). The MDS solution used Kruskal's stress formula 1 (Kruskal, 1964), a Euclidean distance metric, and a monotonic regression function. This MDS solution placed the tokens in a twodimensional space where the distances between tokens were fit into a monotonic function of the $\log$ RT. Preliminary MDS analyses demonstrated that the patterns of results was similar when RT and $\log$ RT were used, but analyses using $\log$ RT accounted for more variance. Furthermore, a previous study has successfully used log RT in the MDS analysis to examine the perceptual organization of vowels (Iverson and Kuhl, 1995). Figure 3 illustrates a two-dimensional MDS solution modeling the perceptual organization of point vowels with a stress of $0.241\left(R^{2}=0.801\right)$.

The results of the MDS solution showed a larger perceptual triangle for vowels rated as good exemplars and a smaller triangle for vowels rated as poor exemplars, thus providing support for the prediction that reduced acoustic vowel working space results in shrunken perceptual space and adversely affects speech intelligibility. As shown in Fig. 3 , the configuration of perceptual vowel organization is similar to the vowel acoustic triangle in the $F 1 / F 2$ space. The perceptual configuration shown in Fig. 3 is consistent with a previous study that employed the MDS solution to examine vowel perceptual space (Singh and Woods, 1971). Moreover, better vowel exemplars composed larger perceptual triangles

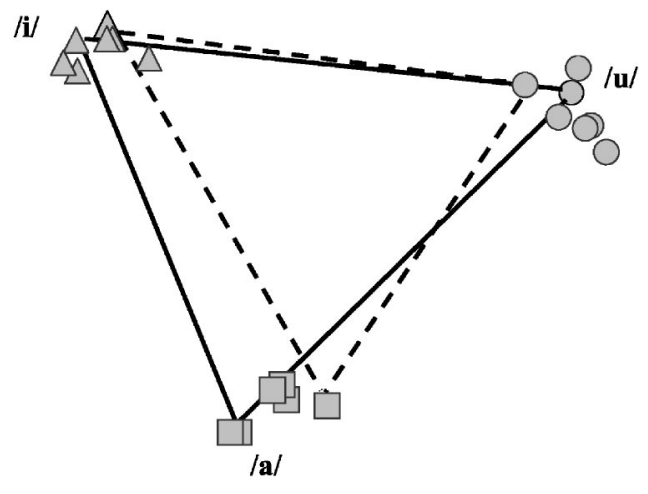

FIG. 3. A two-dimensional MDS solution shows the perceptual organization for perceiving Mandarin vowels. The solid lines connect the best vowel exemplars and dotted lines connect the poorest vowel exemplars.

than poor exemplars. The space formed by the best vowels (3.033 MDS distance ${ }^{2}$ ) is $34 \%$ larger than that of the poorest vowels (2.2653 MDS distance ${ }^{2}$ ). The shrunken perceptual space for vowels with reduced acoustic space further suggests that the reduced acoustic vowel working space of talkers with cerebral palsy decreases the intervowel perceptual distance and adversely affects speech intelligibility.

In addition to examining the effects of reduced acoustic vowel triangles on vowel perceptual space, this study explored within-vowel organization. As shown in the twodimensional MDS solution of perceptual vowel working space (Fig. 3), perceptual clustering is more apparent for the best exemplars, but extended perceptual spacing occurs for the poorest exemplars (except for the poorest /i/). To further examine within-vowel organization, three lower triangular matrices of $\log$ RTs, one for each vowel, were analyzed separately in a one-dimensional MDS solution. The MDS solutions modeled the responses with a stress of $0.253\left(R^{2}\right.$ $=0.757)$ for $/ \mathrm{i} /, 0.236\left(R^{2}=0.790\right)$ for $/ \mathrm{a} /$, and $0.239\left(R^{2}\right.$ $=0.771)$ for $/ \mathrm{u} /$. Figure 4 displays these one-dimensional MDS solutions.

The relative positions of tokens in the one-dimensional MDS solutions (Fig. 4) corresponded similarly to their acoustic locations on the single vector, and, for within-vowel organization, better exemplars were clustered more tightly than the poorer exemplars for the three corner vowel categories. The perceptual clustering and spacing shown in Figs. 3 and 4 can be associated with the "perceptual magnet effect (PME)" (Grieser and Kuhl, 1989; Kuhl, 1991; Iverson and Kuhl, 1995, 1996; Iverson et al., 2003; Miller and Eimas, 1996). The PME posits that phonetic prototypes (i.e., good exemplars) function as perceptual magnets in the perceptual space for phonetic categories; that is, perceptual distance is shrunken around good exemplars, demonstrating greater per-

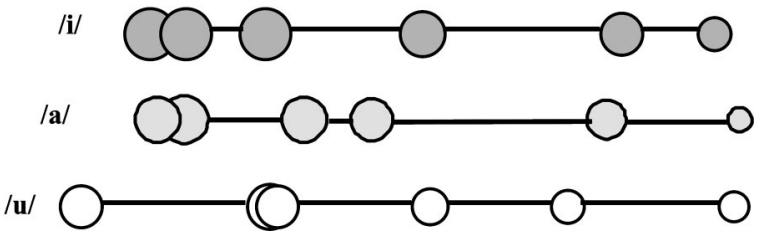

FIG. 4. One-dimensional MDS solutions show the internal organization of Mandarin corner vowels. Circle size corresponds to perceived goodness. 
ceptual similarity; it is extended around poor exemplars, demonstrating less perceptual similarity. The PME might mediate the perceptual distortion shown in Fig. 4, which shows that acoustically equal spacing among vowel variants is unequally mapped onto the perceptual space.

\section{GENERAL DISCUSSION}

The goal of this study was to examine whether the restriction of articulatory movement is associated with the intelligibility of speech produced by Mandarin-speaking young adults with cerebral palsy. The results of acoustic analysis indicate that talkers with cerebral palsy produced a smaller vowel working space area than normal talkers. The reduced vowel working space area reflects the underlying speech problem associated with the speech intelligibility deficit. That is, the more restricted tongue/jaw elevation and anterior-posterior movements contract the vowel working space area. Moreover, for talkers with cerebral palsy, correlational analysis demonstrates a significant association between the vowel working space areas and speech intelligibility, further suggesting that reduced vowel working space area is strongly associated with listeners' difficulty in correctly identifying vowels.

What is the perceptual effect of a reduced vowel working space on listeners' perceptual organization? In experiment 2, we systematically manipulatied vowel working space area. The results of the speech perception experiment indicate that reduced acoustic vowel working space is associated with a reduced perceptual space. Furthermore, the results of the MDS analyses reveal that the category goodness of vowel tokens affects the nonlinear transformation between acoustic space and perceptual space. When examining within-vowel perceptual organization, perceptual clustering is apparent for better vowel exemplars but not poorer exemplars.

\section{A. Relationship between vowel working space area and speech intelligibility}

The present study demonstrates a strong relationship between vowel acoustic space area encompassed by the three corner vowels, and speech intelligibility measured with words produced by Mandarin talkers with cerebral palsy. Therefore, vowel working space area can serve as a general indicator of speech intelligibility. The likelihood of reduced vowel space probably depends on the severity of dysarthria. Measures of vowel working space area have rarely, if ever, been reported for talkers with cerebral palsy. The present study increases our understanding of specific aspects of decreased speech intelligibility in this group of talkers. Larger vowel working spaces were reported to correlate with better speech intelligibility in some talkers without speech disorders (Bradlow et al., 1996), and, some studies have shown reduced vowel working space in English talkers with various types of dysarthria (Turner et al., 1995; Weismer et al., 2001, Ziegler and von Cramon, 1983). The results of the present study are consistent with previous findings on English talkers with similar diagnoses of motor speech impairment, suggesting that the extent of vowel working space could be helpful for representing the level of speech intelligibility across lan- guages. Similar findings among English and Mandarin talkers with dysarthria support the argument that vowel working space has predictive power for speech intelligibility. Moreover, this could be independent of both language and type of dysarthria.

However, in addition to vowel formant distortion, additional speech features that are common in the dysarthric speech secondary to cerebral palsy, such as breathy voice quality, varied vocal intensity, and unstable speaking rate, could also reduce the speech intelligibility of atypical talkers (e.g., Kent et al., 1978). It is possible that an individual's speaking rate might be associated with format variations in experiment 1 . Speaking rate was shown to be related to the perceived intelligibility of talkers with dysarthria (Turner et al., 1995). For example, ALS talkers' sentences were less intelligible when using their fast speaking rate compared to their normal rate. Could speaking rate mediate the relationship between vowel working space area and speech intelligibility shown in this study? When typical talkers and talkers with dysarthria secondary to multiple sclerosis and Parkinson's disease used various speaking rates to read a passage, vowel working space area for their slow speaking rate was significantly larger than that of their normal or fast speaking rate (Turner et al., 1995; Tjaden and Wilding, 2004). In addition, infant-directed speech is characterized by a slower speaking rate and exaggerated pitch variation when compared with adult-directed speech (Fernald and Simon, 1984; Kuhl et al., 1997; Liu et al., 2003). Mothers of different native languages consistently utilize a larger vowel working space area when addressing their infants as opposed to adults (Kuhl et al., 1997; Liu et al., 2003). For typical talkers, however, even though infant-directed speech exhibits larger vowel working space areas than adult-directed speech, an individual's speaking rate, as measured in vowel duration, is not associated with that individual's vowel working space area (Liu, 2002). Results of this study cannot determine whether the individual's speaking rate mediates the association between vowel working space and speech intelligibility because this study did not assess the relative contribution of speaking rate and vowel space to speech intelligibility.

\section{B. Listeners' perceptual organization for reduced vowel working space}

Perceptual characteristics of vowels from a reduced vowel working space are further examined in experiment 2 , where the vowel working space areas were systematically reduced through manipulation of $F 1$ and $F 2$. As predicted from the acoustic analysis on the vowel working space, typical listeners rated tokens from smaller vowel working spaces as poorer exemplars of vowels. In contrast, listeners judged tokens from larger vowel working spaces as better exemplars. Using token-pair similarity judgments, reaction time, and multidimensional scaling to examine the effect of restricted vowel working space on perceptual organization, the poor vowel exemplars or less intelligible tokens were represented with smaller perceptual space areas than good exemplars or more intelligible tokens. In other words, the intervowel perceptual distances of less intelligible vowels were reduced compared to those of more intelligible vowels. 
In addition to revealing the perceptual constraints of perceiving vowels of reduced space, the results of within-vowel perceptual organization showed that the perceptual distance among vowel tokens is reduced near better exemplars but expanded near poor exemplars. This perceptual organization could be due to the perceptual magnet effect (e.g., Kuhl, 1991). Although there is a debate about the source of perceptual distortion and the stability of phonetic prototypes for speech sounds (Frieda et al., 1999; Lotto, Kluender, and Holt, 1998), the results of the current data imply that the perceptual magnet effect might play a role in the perceptual organization of speech sounds. The vowels of talkers with cerebral palsy are judged as poor exemplars or as less intelligible, and are represented in perceptual space farther away from the better exemplars or more intelligible vowels that normal listeners generally encounter and can easily process. Therefore, vowels of talkers with cerebral palsy are not perceptually close to intelligible vowels. Vowels produced by atypical talkers are likely to require listeners to allocate more perceptual resources. This processing inefficiency increases the difficulty when listeners attempt to identify the vowels of cerebral-palsied speakers.

Combining the results of both the acoustic and perceptual experiments, the distorted vowels of talkers with cerebral palsy compose a smaller acoustic space.. The results of our perceptual organization tests demonstrate that vowels from talkers with cerebral palsy are represented with reduced intervowel perceptual distance compared to vowels from typical talkers. This increases the difficulty normal listeners have in mapping the degraded acoustic signals onto existing phonetic categories.

Results of this study provide segmental evidence for reduced intelligibility from both talkers' and listeners' points of view. In addition to the acoustic characteristics of dysarthric speech, listeners' experience helps them to decode the phonetic and lexical information of degraded speech, and this improves speech intelligibility (e.g., Liss et al., 2002). Listening experience can alter the perceptual organization of speech sounds in neurologically intact people. For example, when presented with the same set of stimuli varying in the $F 2$ and $F 3$ of /r/ and /1/ consonants, the perceptual organization of American English speakers is extended along the F3 dimension, the critical acoustic cue distinguishing /r/ from /1/, but Japanese-speaking listeners' perceptual organization was extended along F2 (Iverson and Kuhl, 1996; Iverson et al., 2003). Studies directed towards the relationship between familiarity with degraded acoustical signals and perceptual organization in future studies will not only contribute to theory but also to the clinical goal of designing more efficient programs to help listeners better understand speech produced by talkers with cerebral palsy.

\section{ACKNOWLEDGMENT}

The authors would like to thank Tobey Nelson for her helpful comments on an earlier draft of the manuscript. The efforts of reviewers, especially Gary Weismer, are deeply appreciated.

Ansel, B. M., and Kent, R. D. (1992). "Acoustic-phonetic contrasts and intelligibility in the dysarthria associated with mixed cerebral palsy," J. Speech Hear. Res. 35, 296-308.

Borg, I., and Groenen, P. (1997). Modern Multidimensional Scaling: Theory and Applications (Springer, New York).

Bradlow, A. R., Torretta, G. M., and Posoni, D. B. (1996). "Intelligibility of normal speech. I. Global and fine-rained acoustic-phonetic talker characteristics," Speech Commun. 20, 255-272.

Bunton, K., and Weismer, G. (2001). "The relationship between perception and acoustics for a high-low vowel contrast produced by talkers with dysarthria," J. Speech Hear. Res. 44, 1215-1228.

Burnham, D., Kitamura, C., and Vollmer-Conna, U. (2002). "What's new, pussycat? On talking to babies and animals," Science 296, 1435-1435.

Eimas, P. D., and Miller, J. L. (1992). "Organization in the perception of speech by young infants," Psychol. Sci. 3, 340-345.

Fant, G. (1973). Speech Sounds and Features (MIT Press, Cambridge, MA).

Fernald, A., and Simon, T. (1984). "Expanded intonation contours in mothers' speech to newborns," Dev. Psychol. 20, 104-113.

Fox, R. A. (1983). "Perceptual structure of monophthongs and diphthongs in English,” Lang. Speech 26, 21-60.

Frieda, E. M., Walley, A. C., Flege, J. E., and Sloane, M. E. (1999). “Adults' perception of native and nonnative vowels: Implication for the perceptual magnet effect," Percept. Psychophys. 61, 561-577.

Grieser, D. L., and Kuhl, P. K. (1989). "Categorization of speech by infants: Support for speech-sound prototypes," Dev. Psychol. 25, 577-588.

Hardy, J. C. (1983). Cerebral Palsy (Prentice-Hall, Englewood Cliffs, NJ).

Higgins, C. M., and Hodge, N. M. (2001). " $F 2 / F 1$ vowel quadrilateral area in young children with and without dysarthria," Can. Acoust. 29, 66-68.

Hillenbrand, J., Getty, L. A., Clark, M. J., and Wheeler, K. (1995). "Acoustic characteristics of American English vowels," J. Acoust. Soc. Am. 97, 3099-3111.

HLSYN (1996). Computer software (Sensimetrics Corporation, Cambridge, MA).

Hodge, M. M. (1999). "Relationship between $F 2 / F 1$ vowel quadrilateral area and speech intelligibility in a child with progressive dysarthria," Can. Acoust. 27, 84-85.

Howie, J. M. (1976). Acoustical Studies of Mandarin Vowels and Tones (Cambridge University Press, Cambridge).

Iverson, P., and Kuhl, P. K. (1995). "Mapping the perceptual magnet effect for speech using signal detection theory and multidimensional scaling," $\mathrm{J}$. Acoust. Soc. Am. 97, 553-562.

Iverson, P., and Kuhl, P. K. (1996). "Influences of phonetic identification and category goodness on American listeners' perception of $/ \mathrm{r} /$ and $/ \mathrm{l} /$, , $\mathrm{J}$. Acoust. Soc. Am. 99, 1130-1140.

Iverson, P., Kuhl, P. K., Akahane-Yamada, R., Diesch, E., Tohkura, Y., Kettermann, A. and Siebert C. (2003). "A perceptual interference account of acquisition difficulties for non-native phonemes," Cognition 87, B47-57.

Kent, R. D., Dembowski, J., and Lass, N. J. (1995). "The acoustic characteristics of American English," in Principles of Experimental Phonetics, edited by N. J. Lass (Masby-Year Book, St. Louis, MO), pp. 185-225.

Kent, R. D., Kent, J. F., Rosenbek, J. C., Voperian, H. K., and Weismer, G. (1997). "A speaking task analysis of the dysarthria in cerebellar disease," Folia Phoniatr. Logop. 49, 63-82.

Kent, R. D., Netsell, R., and Abbs, J. H. (1978). “Articulatory abnormalities in athetoid cerebral palsy," J. Speech Hear. Disord. 43, 353-373.

Kent, R. D., Weismer, G., Kent, J. F., and Rosenbek, J. C. (1989). "Toward explanatory intelligibility testing in dysarthria,” J. Speech Hear. Disord. 54, 482-499.

Kewley-Port, D., and Atal, B. S. (1989). "Perceptual differences between vowels located in a limited phonetic space," J. Acoust. Soc. Am. 85, $1726-1740$.

Krause, J. C., and Braida, L. D. (2004). "Acoustic properties ofnaturally produced clear speech at normal speaking rates," J. Acoust. Soc. Am. 115, 362-378.

Kruskal, J. B. (1964). "Multidimensional scaling by optimizing goodness of fit to a nonmetric hypothesis," Psychometrika 29, 1-27.

Kuhl, P. K. (1991). "Human adults and human infants show a "perceptual magnet effect' for prototypes of speech categories, monkeys do not," Percept. Psychophys. 50, 93-107.

Kuhl, P. K., Andruski, J. E., Chistovich, I. A., Chistovich, L. A., Kozhevnikova, E. V., Ryskina, V. L., Stolyarova, E. I., Sundberg, U., and Lacerda F. (1997). "Cross-language analysis of phonetic units in language addressed to infants," Science 277, 684-686.

Ladefoged, P., and Maddieson, I. (1996). The Sounds of the World's Languages (Blackwell, Malden, MA). 
Liberman, A. M., Harris, K. S., Kinney, J. A., and Lane, H. L. (1961). "The discrimination of relative-onset time of the components of certain speech and nonspeech patterns," J. Exp. Psychol. 61, 379-388.

Lindblom, B. (1990). "Explaining phonetic variation: A sketch of $\mathrm{H}$ and $\mathrm{H}$ theory," in Speech Production and Speech Modeling, edited by W. J. Hardcastle and A. Marchal (Kluwer Academic, Dordrecht, The Netherlands), pp. 403-439.

Liss, J. M., Spitzer, S. M., Caviness, J. N., and Adler, C. (2002). "The effects of familiarization on intelligibility and lexical segmentation in hypokinetic and ataxic dysarthria." J. Acoust. Soc. Am. 112, 3022-3030.

Liu, H.-M. (2002). "The acoustic-phonetic characteristics of infant-directed speech in Mandarin Chinese and their relation to infant speech perception in the first year of life," unpublished Ph.D. dissertation, University of Washington.

Liu, H. M., Kuhl, P. K., and Tsao, F. M. (2003). "The association between mothers' speech clarity and infants' speech discrimination skill,' Dev. Sci. 6, F1-F10.

Liu, H. M., Tseng, C. H., and Tsao, F. M. (2000). "Perceptual and acoustic analysis of speech intelligibility in Mandarin-speaking young adults with cerebral palsy," Clin. Linguist. Phon. 14, 447-464.

Lotto, A. J., Kluender, K. R., and Holt, L. L. (1998). "Depolarization the perceptual magnet effect,” J. Acoust. Soc. Am. 96, 2076-2087.

McDonald, E. T. (1987). "Cerebral palsy: Its nature, pathogenesis, and management," in Treating Cerebral Palsy, edited by E T. McDonald (Pro-Ed, Austin, TX), pp. 1-19.

Miller, J. L., and Eimas, P. D. (1996). "Internal structure of voicing categories in early infancy," Percept. Psychophys. 58, 1157-1167.

Peterson, G., and Barney, H. (1952). "Control methods used in a study of the vowels," J. Acoust. Soc. Am. 24, 175-184.

Platt, L. J., Andrews, G., and Howie, P. M. (1980). "Dysarthria of adult cerebral palsy. II. Phonemic analysis of articulation errors," J. Speech Hear. Res. 23, 41-55.

Platt, L. J., Andrews, G., Young, M., and Quinn, P. T. (1980). "Dysarthria of adult cerebral palsy. I. Intelligibility and articulatory impairment," J. Speech Hear. Res. 23, 28-40.

Remez, R. E. (2001). "The interplay of phonology and perception considered from the perceptive of perceptual organization," in The Role of Speech Perception in Phonology, edited by E. Hume and K. Johnson (Academic, San Diego, CA), pp. 27-52.

Shepard, R. (1972). "Psychological representation of speech sounds," in Human Communication: A Unified View, edited by E. E. David and P. B. Denes (McGraw Hill, New York), pp. 67-113.

Singh, S., and Woods, D. R. (1971). "Perceptual structure of 12 American vowels," J. Acoust. Soc. Am. 49, 1861-1866.
Stevens, K. N. (1998). Acoustic Phonetics (MIT Press, Cambridge, MA).

Takane, Y., Young, F. W., and De Leeuw, J. (1977). "Nonmetric individual differences multidimensional scaling: An alternating least-squares method with optimal scaling features," Psychometrika 42, 7-67.

Tjaden, K., and Wilding, G. E. (2004). "Rate and loudness manipulations in dysarthria: Acoustic and perceptual fundings," J. Speech Lang. Hear. Res. 47(4), 766-783.

Tseng, C.-Y. (1990). An Acoustic Phonetic Study on Tones in Mandarin Chinese (Institute of History \& Philology Academia Sinica, Taipei, Taiwan).

Turner, G. S., Tjaden, K., and Weismer, G. (1995). "The influence of speaking rate of vowel working space and speech intelligibility for individuals with amyotrophic lateral sclerosis," J. Speech Hear. Res. 38, 1001-1013.

Weismer, G., and Martin, R. E. (1992). "Acoustic and perceptual approaches to the study of intelligibility," in Intelligibility in Speech Disorders: Theory, Measurement, and Management, edited by R. D. Kent (John Benjamins, Amsterdam, The Netherlands), pp. 67-118.

Weismer, G., Martin, R. E., Kent, R. D., and Kent, J. F. (1992). "Formant trajectory characteristics of males with amyotrophic lateral sclerosis," J. Acoust. Soc. Am. 91, 1085-1098.

Weismer, G., Jeng, J-Y., Laures, J. S., Kent, R. D., and Kent, J. F. (2001). "Acoustic and intelligibility characteristics of sentence production in neuorgenic speech disorders," Folia Phoniatr. Logop. 53, 1-18.

Weismer, G., Laures, J. S., Jeng, J-Y., Kent, R. D., and Kent, J. F. (2000). "Effect of speaking rate manipulations on acoustic and perceptual aspects of the dysarthria in amyotrophic lateral sclerosis." Folia Phoniatr. Logop. 52, 201-219.

Whitehill, T. L., and Ciocca, V. (2000). "Perceptual-phonetic predictors of single-word intelligibility: A study of Cantonese dysarthria," J. Speech Hear. Res. 43, 1451-1465.

Wu, J. T., and Liu, I. M. (1987). "A study on the sound properties and semantic classifications of Chinese words," Research report of National Science Council, Republic of China (Taiwan).

Yorkston, K. M., Beukelman, D. R., and Bell, K. R. (1988). Clinical Management of Dysarthric Talkers. (Little, Brown, Boston).

Yorkston, K., Dowden, P. A., and Beukelman, D. R. (1992). "Intelligibility measurement as a tool in the clinical management of dysarthric talkers," in Intelligibility in Speech Disorders: Theory, Measurement, and Management, edited by R. D. Kent (John Benjamins, Amsterdam, The Netherlands), pp. 265-285.

Ziegler, W., and von Cramon, D. (1983). "Vowel distortion in traumatic dysarthria: A formant study," Phonetica 40, 63-78.

Ziegler, W., and von Cramon, D. (1986). "Spastic dysarthria after acquired brain injury: An acoustic study," Br. J. Disord. Commun. 21, 173-188. 